\title{
Design, Fabrication, and Testing of an Electromechanical High- Temperature Tensile Test Machine
}

\author{
Taif Y. Ghadhban ${ }^{a *}$, Hussain J.M Al-ALkawi ${ }^{b}$, Ahmed H. Reja (D) c \\ ${ }^{a}$ University of Technology, Baghdad, Iraq, 51835@student.uotechnology.edu.iq \\ ${ }^{\text {b } U n i v e r s i t y ~ o f ~ T e c h n o l o g y, ~ B a g h d a d, ~ I r a q, ~ 50089 @ u o t e c h n o l o g y . e d u . i q ~}$ \\ ${ }^{\mathrm{c}}$ University of Technology, Baghdad, Iraq, 50073@uotechnology.edu.iq \\ * Corresponding author.
}

$\begin{array}{lll}\text { Submitted: } 03 / 11 / 2020 & \text { Accepted:26/12/2020 Published: 25/04/2021 }\end{array}$

K E Y W O R D S

Chamber Design,

Machine Design,

High Temperature,

Tensile test

AA6163-T6

\section{A B S T R A C T}

The following paper presents a developed design and manufacturing of a servo-driven Electromechanical high-temperature tensile machine with an integrated environmental chamber. The maximum load capacity is set to be $20 \mathrm{kn}$ with the possibility of future upgrades. The machine is automated by a computerized system that controls the entire operation of the designed machine. It is designed to be capable for testing a variety of materials at various temperatures ranging from room temperature up to $500^{\circ} \mathrm{C}$. The machine was fully controlled using automated software to control the entire operation and to provide users with a certified test report. The main component is a high-quality aluminum frame that hosts the entire setup, like a furnace, and a universal type gripping mechanism. The structure is monitored by precise measurement instrumentation and a dependable data acquisition system. The machine was validated by testing AA6063-T6 to evaluate the sophistication of the machine's functionality. The results then compared to an international standard, provided close results with a low percentage error of about $4.5 \%$ compared to international standard readings.

How to cite this article: T. Y. Ghadhban, H. J. Al-Alkawi, and A. H. Reja, "Design and Fabrication of an Electromechanical High-

Temperature Tensile Test Machine," Engineering and Technology Journal, Vol. 39, Part A, No. 04, pp. 614-624, 2021.

DOI: https://doi.org/10.30684/etj.v39i4A.1911

This is an open access article under the CC BY 4.0 license http://creativecommons.org/licenses/by/4.0

\section{INTRODUCTION}

Tensile testing at elevated temperature is defined as the reliable method of testing the mechanical properties of materials as a function of temperature. Properties such as the yield and ultimate tensile strength, elastic modulus, and elongation in which they represent important factors for engineering designs [1]. High-temperature properties of materials are an essential concern in a variety of applications like power plant generation equipment, the automotive industry, and aerospace. These 
components will almost definitely experience elevated temperature [2]. As a result, this high temperature shall induce thermal stress which causes failure of components. Consequently, the tensile test is performed necessary for engineering designs to understand the behaviors of the materials when it is subjected to a high-temperature. This will assist the designer to provide accurate data to manufacture the proper components for the specific application. Therefore, a dependable platform is required to conduct this kind of test . This platform is usually called a Universal platform or UTM machine (Universal Testing Machine). Previous as well as current devices are heavier, take a long time to test materials, as well as high energy consumption. It is not equipped with an oven for high-temperature tests. In addition to its reliance on mechanical and electrical devices instead of automation or computing by external computers, and this is what made it complex and requires an expensive periodic calibration and maintenance. Operating these devices requires a set of skills. In addition to be ing designed to produce graphical results. Any test result report is presented in the form of charts. So she required graph reading skills. This current invention focuses on designing a computerized device that is monitored by carefully designed algorithms in addition to a set of sensors, which makes it easy to operate and mainta in, which gives fast, accurate, and reliable results, thus greatly reducing costs. In terms of the properties of materials in standard databases, they often came through conducting tests at room temperature, which differ completely and greatly when the material was exposed to a high temperature because many properties of the material depend on the temperature. In general, the strength of the material has a proportional relationship with the heat. In the case of an increase in the temperature, the strength of the material decreases, which causes a decrease in the basic energy responsible for initiating the plastic behavior of the material, while causing an increase in the ductility of the material. Besides, structural changes such as recrystallization, stress aging, and precipitation may appear at specific temperature ranges. Therefore, to examine the behavior of materials under high temperatures, the material must be subjected to a tensile test under a certain temperature range and simultaneously. The device was designed based on this basis. Most of the relevant previous similar work has been carefully studied, and it has been discovered that most of the designed devices are effectively manufactured while providing decent acceptable results. However, most of them are nothing but rudimentary demonstration devices that lack many laboratory capabilities and features. Woong Lim \& Ho-Kyung (Kim) [3] the research involved manufacturing an illustrative miniature tensile device that uses miniature samples and performs tensile tests only at room temperature. Capable of testing metallic materials at high temperatures, but the effective tensile distance was very short due to the small structure of the furnace design. In addition to the design of the small sample holder, this holder allows testing of specially manufactured samples to match the type of holder used only. Noor Rahman [4] design and manufacture a machine for testing the tensile and hardness testing of samples. The device showed acceptable results, but it is a prototype that lacks much development to upgrade to a device that can withstand laboratory conditions and repeated tests. Finally, Dr. Jacob Bishop [5] from the University of Nebraska, USA, worked on designing a model for a low-cost, miniature tension device, to perform tensile tests under room temperature only. This is to help students understand the basic simple properties of materials, and for students also to be able to relate exercise to the practical aspect. The device does not rise to an integrated laboratory apparatus as it is still only a prototype lacking a lot of features. After a careful and thorough study of the previous research and the current commercial devices. Work has been done on designing the device in question. What distinguishes the manufactured device from other researchers and the current equipment is that the manufactured device is an integrated device that uses a fully functional integrated oven, supported by a powerful and accurate PID (Proportional Integral Derivative) controller that can quickly reach the desired temperature. The oven is very flexible, it can be attached/detached to the loading frame easily. The device performs the tests in linear motion and with a high level of accuracy due to the high-quality standard components. The device can process and collect data quickly and accurately due to the sophisticated microcomputer. The device can withstand laboratory conditions and repeated checks.

\section{DESIGN IDEA}

The designed machine shall perform high-temperature tensile testing on a universal platform with a high-temperature testing furnace attached to it. To achieve efficiency and fast performance, the furnace shall raise the temperatures. Consequently, the specimens will be pulled at the same time. 
The test can be accomplished at temperatures close to $752{ }^{\circ} \mathrm{F}, 400$ Celsius. A proportional Integral Derivative (PID) controller was put in service to control the furnace temperature and to guarantee a sophisticated level of functionality. The change in mechanical properties has a proportional relationship with heat rising. Formerly the computerized machine system works to heat the specimen to the set point desired temperature, then allows it to soak trying to mimic hot environment application and also for more accurate results. [4,5]

\section{MAChINe Design}

There are three major steps involved when designing the UTM.

1) Loading frame unit

2) Materials and electrical component selection

3) Oven environmental chamber (design and fabrication)

\section{Load unit design}

The Load unit is the most critical component of the system because it determines the base capacity and hosts the entire setup, one of the most important components that the frame host are the control board, a belt-pully driven system that is powered by a servo motor, ball screw drive rods [8]. The frame was made as double support which is more stable by design nature [5]. The load Frame supported a hard table that indeed can be used to compress the specimen. This feature was made specifically for future development.

The machine crosshead can move up and down to deliver force to the sample, The crosshead moves by a mixture of a "motor and gear reducer system" It uses a rotating ball screw to drive a loadbearing crosshead up and down that approach provides an accurate and liner precise motion [9]. Figure 1 illustrates the Ball screwdriver. The machine is servo belt-driven. The servomotor supported by a speed reducer powers a series of pulleys and gears which move the screws, resulting in the crosshead moving. Machines with a higher capacity than $200 \mathrm{kn}$, use two reducers (one per ball screwdriver), to increase the mechanical gain and assure the needed torque. The motion of the servo motor is controlled by an Ac servo drive system which communicates with the controller works as a complete computer. Figure 2 presents the load unit after fully assembled.

The servomotor speed is relational, the test rate and motor speed are controlled by increasing the voltage to the power amplifier [10].

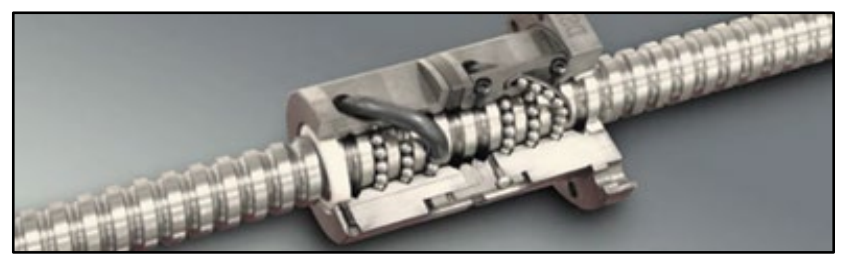

Figure 1: Ball screw driver

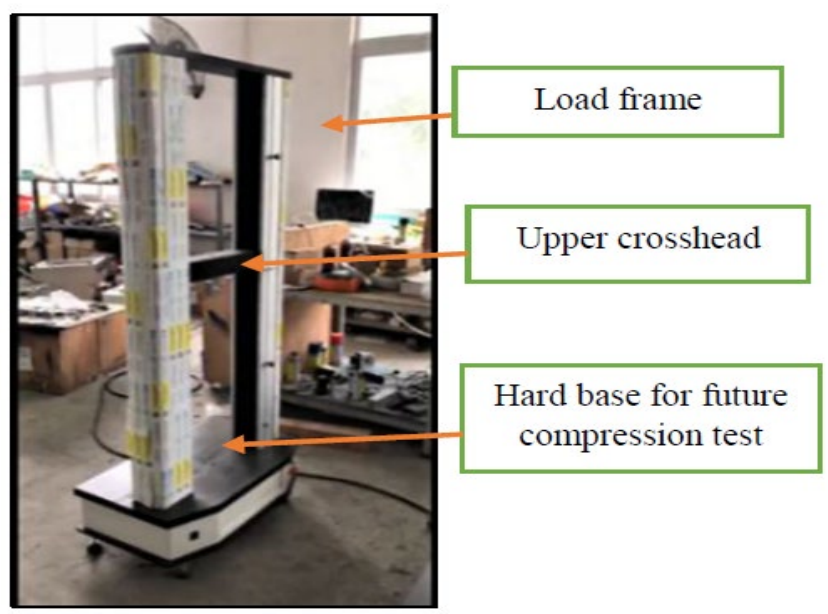

Figure 2: Load frame 
An easy regulation for the variate motor speed amplifier is presented below (the difference between the actual and desired test speed). The computer system controls the servo motor to rotate through the controller through the speed control system. The beam is driven by the lead screw after deceleration, to complete the ascending and descending; tensile tests.

$$
\begin{gathered}
\text { "Test Speed Error }=\text { Desired Test Speed }- \text { Actual Test Speed" } \\
\text { "Amplifier Voltage }=\text { Kp x Test Speed Error" }
\end{gathered}
$$

"Where Eq. 2 represents the proportional control algorithm. $\mathrm{Kp}$ is the proportional ga in and is tuned to minimize error" [11].

\section{Materials selection}

Due to the lack of local dependable sources and suppliers, most of the electrical, mechanical, and measurement components were selected with extra thoughts and questions to ensure the meeting of the main objective of the research which is accuracy and reliability. Therefore, the competent were ordered directly and personally from international markets in different countries.

\section{Oven design and fabrication}

The designed oven is a thermomechanical apparatus that produces heat to heat the spaceman within the chamber, causing a mechanical change to the sample. Oven heating efficiency relies generally on "three major components which are, heating elements, the insulation layer, and the proportional integral derivative (PID) controller". The oven was designed and set to be a laboratory furnace, making the max temperature limited to $500^{\circ} \mathrm{C}$. The materials used to manufacture the box were locally secured. Figure 3 demonstrates the materials uses for oven fabrication. Substantial work was made to achieve furnace

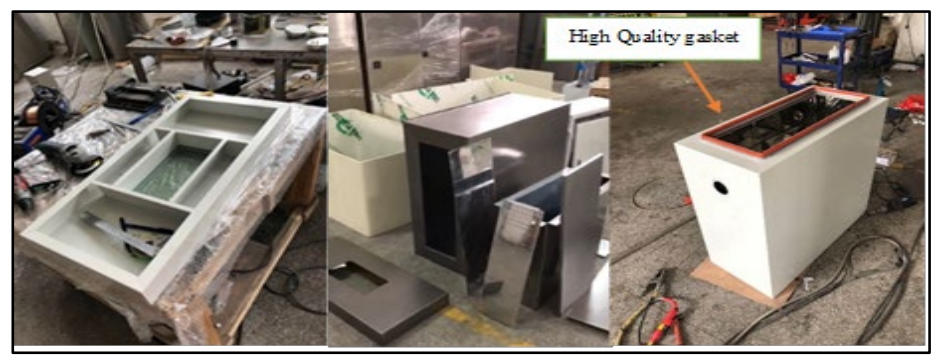

Figure 3: Oven outer/inner chamber materials

integration with the $20 \mathrm{kn}$ tensile testing machine load frame. Figure 4. These adjustments involved the mounting of the furnace in the setup, chamber isolation, control board fitting and wiring, calibration of the grip's rods, manufacturing of a split specimen gripping, and the oven front door. High strength steel hinges that handle high temperatures are used to attach the door to the environmental chamber structure. During the test, the chamber door can be firmly locked using a strong locker to avoid heat escape testing, besides a high-quality gasket was fitted to the outside of the oven door.

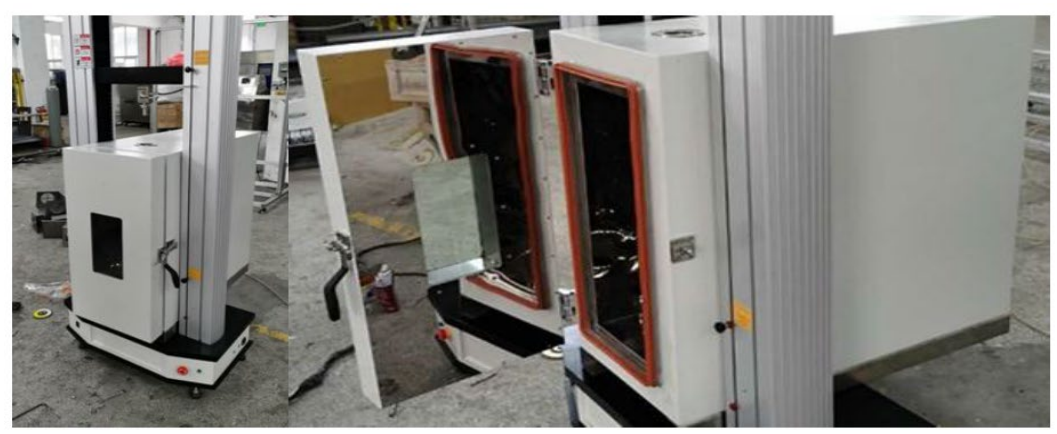

Figure 4: Final machine with the integrated oven 


\section{Heating Element Design Equations}

The set of equations used for specifications calculations are as followed"

$$
\begin{gathered}
“ \mathrm{H}=5.72 \mathrm{ke}\left[\left(\frac{\mathrm{T}_{1}}{100}\right)^{4}-\left(\frac{\mathrm{T}_{2}}{100}\right)^{4}\right] \frac{\mathrm{w}}{\mathrm{m}^{2}} \\
\mathrm{~A}_{\text {CROSEC }}=\pi \mathrm{r}^{2}=\frac{\pi \mathrm{d}^{2}}{4} \\
\mathrm{~A}_{\text {CIRCUm }}=\pi \mathrm{dI} \\
\mathrm{C}=\mathrm{H} * \mathrm{~A} \\
\mathrm{R}=\frac{\rho \mathrm{I}}{\mathrm{A}} \\
\mathrm{P}=\frac{\mathrm{v}^{2}}{\mathrm{R}} \\
\mathrm{I}=\frac{\mathrm{v}^{2} \mathrm{~d}^{2} \pi}{4 \mathrm{P} \rho} \\
\mathrm{P}=\mathrm{H} \pi \mathrm{dI} \\
\therefore \mathrm{I}=\sqrt{\frac{\mathrm{dv^{2 }}}{4 \mathrm{Hp}}}
\end{gathered}
$$

"H: Heat radiated, (W/m2);

T1- Heating source temperature $(\mathrm{K})$;

T2- Surface to be heated temperature $(\mathrm{K})$;

k- Radiation efficiency;

e-constant- Emissivity"

"l- stands for length in (m) while R is resistance in $(\Omega / \mathrm{m})$; then $\rho$ - for resistivity measured in $(\mathrm{m} 2 / \Omega)$ and P- Power stands for in (W); finally, V, d, C, A goes for voltage, dimeter, heat respectively, and area".

Calculations:

$$
\text { “T2 }=400^{\circ} \mathrm{C}=673 \mathrm{~K} \quad \mathrm{~T} 1=800^{\circ} \mathrm{C}=1073 \mathrm{~K} ; \mathrm{e}=0.9 ; \rho=1.35 \times 10-6 ; \mathrm{k}=0.51 ; "
$$

" $\mathrm{P}=770 \mathrm{~W}$ desired power rating for the system. Hence $770 / 2=385 \mathrm{~W}$. Power for each heating tube $\therefore \mathrm{H}=29416 \mathrm{~W} / \mathrm{m}^{2 \prime \prime}$

According to the given equations " $\mathrm{d}=0.61 \mathrm{~mm}$. The cross-sectional area is $2.83 \times 10^{-7} \mathrm{~m}^{2}$ for $\mathrm{D}$ alloys of $d=0.6 \mathrm{~mm}$. Equating Eq (9) and (11) so that one can be able to determine the diameter of the optimum Kanthal wire" (heating element). Calculations were made for the wire diameter can be determined and manufacturing dimensions [12].

\section{Chamber Temperature Test and Control}

The temperature is controlled by a PID controller to guarantee an optimum performance of heat control. One of the reliable test methods followed to test the oven was rising the oven temperature to maximum possible values and then investigate oven behavior at this point such as oven structure practicality, personnel safety, and external oven temperature to examine the effectivity of the insulation layers. $400^{\circ} \mathrm{C}$ was the set design value. Primarily, SV was set to $400{ }^{\circ} \mathrm{C}$. Formerly the PID was tweaked. The temperature was held for 50 minutes. The drive for this kind of testing was to reach the ideal PID values for maximum operation temperature and ideal PID values for the ideal external oven temperature. The reached idyllic values were set as the optimum limits that the oven must work under [12]. Thermal power control can be performed in two ways: ON-OFF and PID control in closed-loop mode [13]. Both control ways provide a significant difference in responses in terms of energy efficiency. Consistency in energy flow that results in a variable process is 
temperature value. This section presents a PID-based oven temperature control that used a PID algorithm. The desired temperature is set by the user using the HMI, the PID, will try to minimize the error value as the difference between the desired temperature and measured temperature [14] by adjustment of a control variable then taking the data from a temperature sensor (PT100), and astutely implementing the PID controller through a PID that is based on the differences in response times of the oven. The goal of the control is to equate the output signal to the desired value.

\section{Oven Testing Procedure}

For system behavior monitoring, one terminal end of the thermocouple of the GLX explorer data logger was injected inside the oven over the upper hole so it can investigate the actual temperature readings (PV). While the other terminal end was located strictly to the oven's RTD so that they sense the identical temperature at the same position inside the oven. The max temperature that the thermocouple of the GLX data explorer survives is $110^{\circ} \mathrm{C}$. Therefore, tests were achieved below $110^{\circ} \mathrm{C}$.

Now the probe of the oven has another thermocouple placed next to it as close as possible with no contact, as a contact will affect readings. For the data to be excessed before powering the oven and collect temperature, the chamber must be turned off while the GLX explorer is on. The collected data were detected as graphs on the GLX data explorer. The test must keep operating until the oven set point is reached as well as reaching a steady-state condition. Meanwhile, the process of data collection must take at least $10 \mathrm{~min}$ to be able to tell the duration that the system needs to be stabilized. Afterward, the collected data passed to the governed computer for analysis. This process stays repetitive until optimal values are collected.

\section{TM2101 SOFTWARE}

The electronic drive control software of the UTM is comprehended via an advanced microcomputer armed with a 32-bit ARM processor. While TM2101 software is used to control machine operation and the measurements control. Metals and non-metal materials can be tested in the current system and the test is compatible with international standards as the software support variety of test standards and materials. The user-friendly interface is supported with features like automatic certified reports conferring to user needs, real-time measurement, abstract processing of data, report printing, real-time measurement, the demonstration of force at the peak, displacement at peak, and extra functions. The main features involved in the software can perform observation zoom. Also, it complies with lots of test methods together with many closed-loop control modes, open-loop constant displacement, and constant speed stress. The automatic calibration, as well as effortless operation, advances the dependability of the machine significantly. The control structure is armed with an automatic shutdown function and overload protection for safe operation. A huge quantity of different test processing data is supported by the TM2101, this feature enables the software of detecting a great quantity of data in instantaneous timing and ensuring data communication to the PC between USB communication ports and the PC. The control parameters are auto-tuned in instantaneous timing according to tension/strain and force measured values during the test. Due to that the need for initial testing is eliminated which makes it easy to perform extremely exact stressstrain-control. Ideal measurement parameters are used to attained data, The Data for samples with unidentified strength can still be attained. Besides specifying an amplifier range is not needed for strain measurement.

\section{TeSt EXPERIMENTAL ReSUlts}

\section{Room temperature test}

The machine passes the initial test with decidedly no issues. Besides, it shows a remarkable response and high functionality level. Initially, the machine performed a tensile test at $30^{\circ} \mathrm{C}$ by using AA6063-T6. The test specimens were prepared according to ASTM (American society for testing and materials) E8M-16a. See Figure 5. 


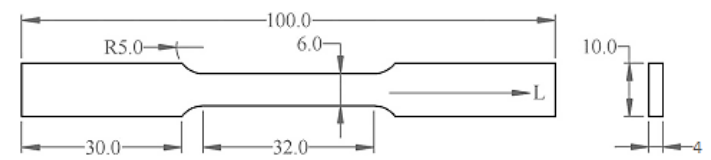

Figure 5: AA6063-t6 specimen comply with ASTM-E8M-16a

To ensure an accurate reading three samples of AA6063-T6 were used, as seen in Figure 6. The test results have been illustrated both in Table I and Figure 7, a comparison has been made between the machine results and the certified standard.

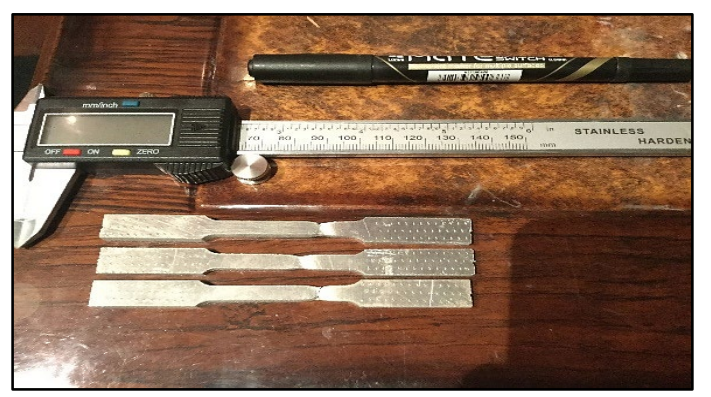

Figure 6: Tested specimens

TABLE I: Room Temperature Tensile Test Results

\begin{tabular}{ccccccc}
\hline \hline $\begin{array}{c}\text { Mechanical } \\
\text { properties }\end{array}$ & $\mathbf{A}$ & $\mathbf{B}$ & $\mathbf{C}$ & Mean & $\begin{array}{c}\text { \% } \\
\text { Erro } \\
\mathbf{r}\end{array}$ & $\begin{array}{c}\text { Certified } \\
\text { Standard } \\
\text { (ASM) }\end{array}$ \\
\hline Yield Strength (MPa) & 197 & 195.310 & 195.100 & 195.80 & 4.5 & 205 \\
\hline Ultimate Tensile & 228. & 226.901 & 231.560 & 228.98 & 4.6 & 240 \\
Strength (MPa) & 479 & & & & & \\
\hline \%Elongation & 20.3 & 20.618 & 18.234 & 19.8 & 5.7 & 21 \\
& 82 & & & & & \\
\hline
\end{tabular}

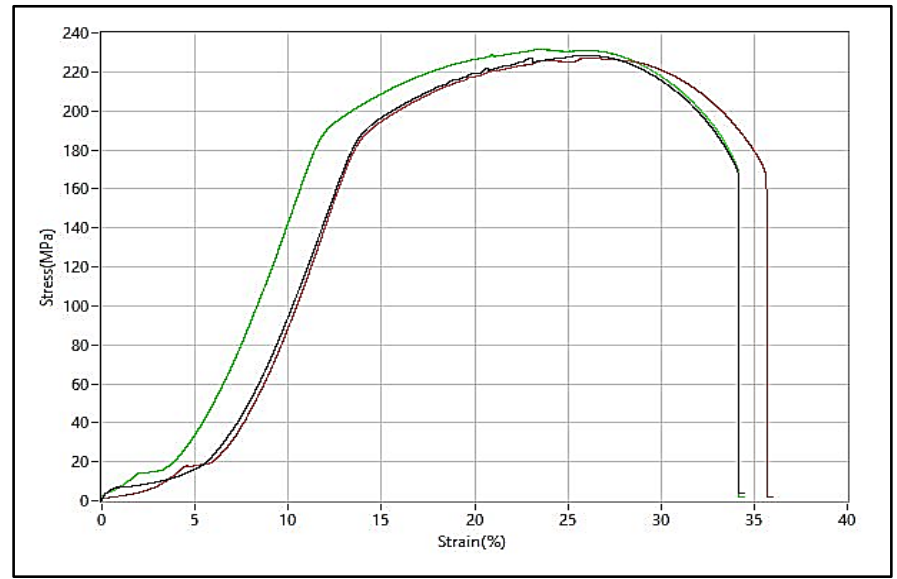

Figure 7: Stress-strain curve of room temperature test

\section{High-Temperature Tensile Test}

The test was conducted according to the ASTM standers handbook. Aluminum AA6063-T6 with another specimen geometry was used in this test. Figure 8 demonstrates the standard specimen.

The specimens were tested at (180-230-300) ${ }^{\circ} \mathrm{C}$. As illustrated in Figure 9, The specimens were socked for about 10 minutes. Subsequently, the test was commenced. Stress-strain curve illustrated in Figure 9. The analysis of the test data was presented in Table II. 


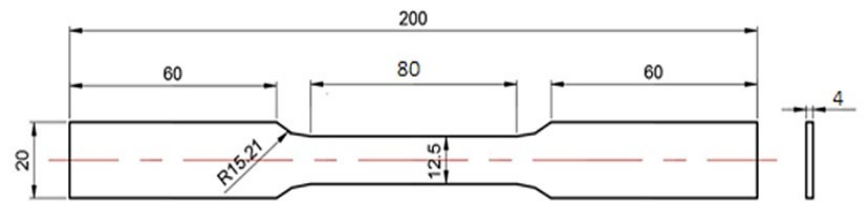

Figure 8: Alternative specimen geometry was used to study geometry affection on results

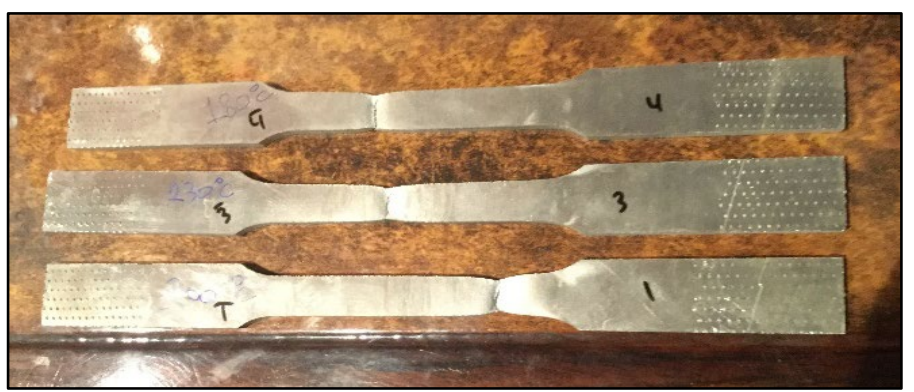

Figure 9: Specimens were tested at different temperatures.

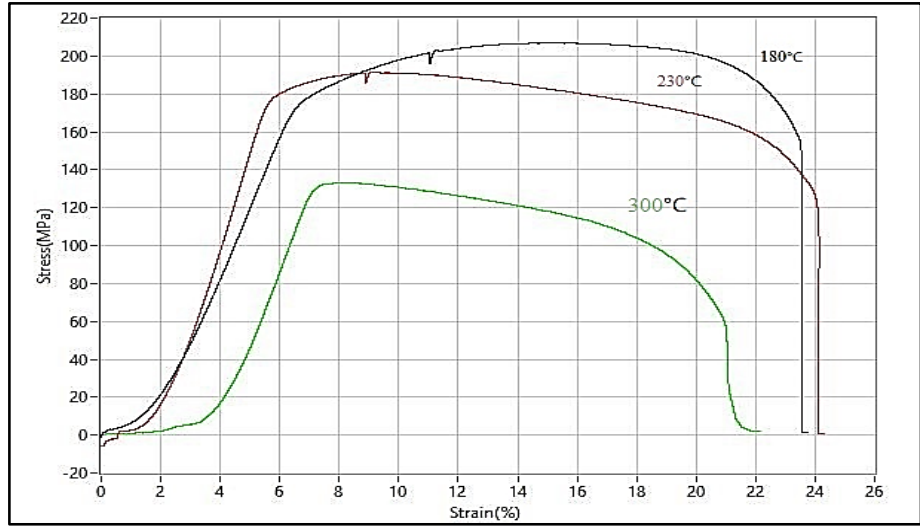

Figure 10: Specimens were tested at different temperatures.

TABLE II: High-Temperature Tensile Test Results

\begin{tabular}{ccccc}
\hline \hline Temperature ${ }^{\circ} \mathrm{C}$ & $\begin{array}{c}(\mathbf{R T}) \\
\text { The mean reading }\end{array}$ & $\mathbf{1 8 0}$ & $\mathbf{2 3 0}$ & $\mathbf{3 0 0}$ \\
\hline Ultimate Stress MPa & 228.98 & 206.952 & 191.355 & 133.061 \\
\hline \%Reduction In strength RS & & 9.6 & 17.3 & 42.5 \\
\hline
\end{tabular}

\section{DisCUSSIONS}

It is absorbed from the curves in Figure 7, that the material shows a similar trend at the level of yie ld and UTS (Ultimate tensile strengths) which means a stable result. For the specimens tested, the Ultimate strength was recorded at about $231 \mathrm{MPa}$. Yield strength recorded at about $205 \mathrm{MPa}$ with acceptable percentage errors compare to ASM standard (American society for metals). It demonstrated a consistent stable behavior. Different specimen geometry has been tested at room temperature to investigate size affection on the result. It was found that specimen size has a negatable effect on Ult imate strength and yie ld strength. As demonstrated in In Figure 9, the first specimen was tested at $180{ }^{\circ} \mathrm{C}$, the strength was reduced to $9.6 \%$. The $300{ }^{\circ} \mathrm{C}$ had the greatest effect on the strength of the AA6063-T6. The strength was reduced to $42.5 \%$ from the room temperature tested value. For this temperature, even at low times, a rapid decrease in strength occurs. Table II shows the ultimate strength reduction. Figure 11 demonstrates UTS variation with high heat. UTS decreased with increasing temperature and vice versa. It was noticed that material softening developed temperature sensitivity during temperature rising. This means that material softening getting stronger when the 
temperature increased, to the fact of dynamic recovering (DRV) as well as dynamic recrystallization (DRX) which leads to easier deformation. All of that reflects the stable dependable operation.

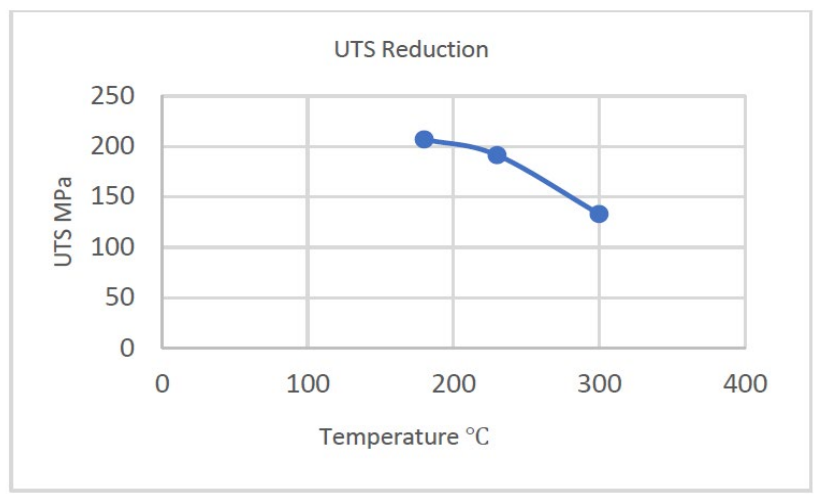

Figure 11: The reduction in ultimate strength (UTS) as temperature rises.

\section{RESULTS COMPARISON}

The results were compared to a work conducted by a professional machine H50KS UTM, displaying a close result or trend with a slight variance due to the different strain rates used in the two machines as shown in Figures 12 and 13. According to the reference, the strain rate affects the ultimate strength significantly [15].

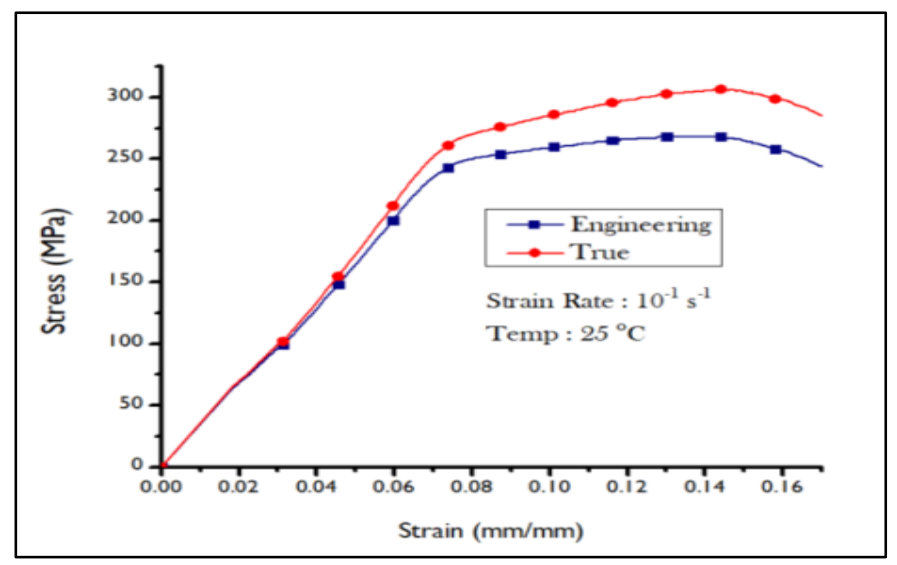

Figure 12: Engineering and true strain-stress curve of AA6063-T6 for H50KS UTM [15]

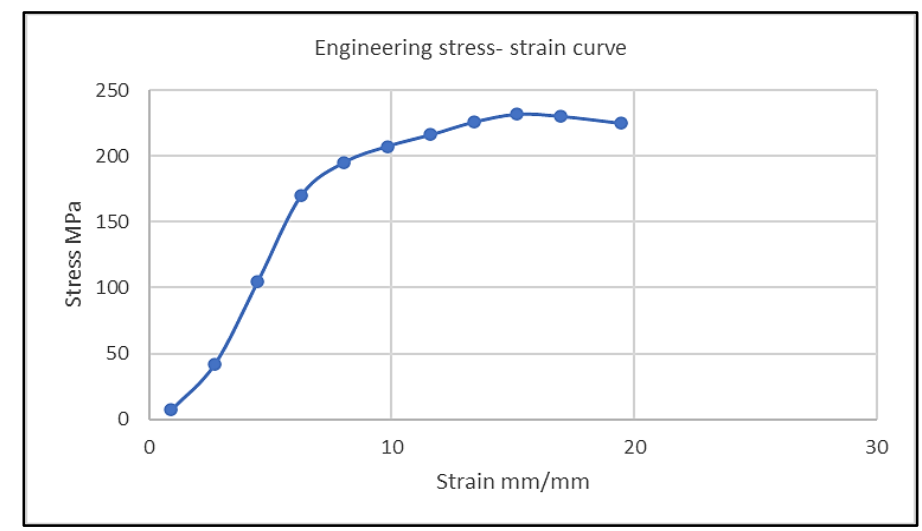

Figure 13: Engineering stress-strain curve of AA6063-T6 at $32^{\circ} \mathrm{Cfor}$ the fabricated UTM 


\section{CONCLuSiON}

The engineering enhancements have made the machine performs the tasks smoothly and accurately giving fast results. Oven integration of the machine was achieved successfully. From a cost perspective, the machines offer competitive features and specifications at a low cost. A commercial machine like this with almost the same essential specification will cost almost $45,000 \$$ USD. Thanks to the correct and well-thought-out selection and arrangements of the most important parts inside the machine. This was achieved from extensive work and research. One of the important features that the machine achieved, is the ability to transition from elevated temperature to lower or indoor temperature, to be able to test other specimens. The chamber was designed and assembled to reach the setpoint temperature quickly, thanks to the PID, the well-thought-out insulation, and the seals' door system. Test time is remarkably reduced compared to the old school machine. That goes to the functionality and the computer used to control the machine. This electromechanical machine has been provided with leading features just like these found in international brands, but the most important one of these is compliance with international standards. Therefore, this machine shall enable and assists students and researchers at The electromechanical engineering department to perform high-temperature tensile test reliably with accurate and rapid time results. Finally, it is recommended to use an extensometer during the test for ultra-precision results.

\section{References}

[1] N. Merah, F. Saghir, Z. Khan, A. Bazoune, Effect of temperature on tensile properties of HDPE pipe material, Rubber. Compos., 35 (2006) 226-230. https://doi.org/10.1179/174328906X103178

[2] R. Donovan, R. Fortune, R. Trout, Elevated temperature effects on the mechanical properties of age hardened 6xxx series aluminum alloy extrusions, Mater. Eng. Dep. California State University, San Luis Obispo, 2015.

[3] W. Lim , H. K. Kim, Design and development of a miniaturised tensile testing machine, Glob. J. Eng. Educ., 15 (2013) 48-53.

[4] N. Rahman, W. U. Rahman, M. Shahid, Design and fabrication of compact tension fracture toughness testing machine, Res. Dev. Mach. Des., 1(2018)6-11.

[5] J. Bishop, BYOE: A low-cost material testing machine to increase engagement in a materials science lab course, in ASEE AnnualConf. Exp. Conf. Pro., 2017 (2017). http://dx.doi.org/10.18260/1-2--27993

[6] P. Tiernan, G. O'Connor, Design, manufacture and test of a high temperature tensile and compression testing device, Elsevier, Procedia Manuf. 17 (2018) 672-679. https://doi.org/10.1016/j.promfg.2018.10.116

[7] M. N. Su, B. Young, 10.37: Mechanical properties of high strength aluminium alloy at elevated temperatures, Ernst . Sohn, Department of Civil Engineering, The University of Hong Kong, Hong Kong, China, Ce/Papers. 1(2017) 2831-2839. https://doi.org/10.1002/cepa.334

[8] R. Rinefierd, E. Kastner, N. G. Currier, B. Stuart, E. Brunner, K. Mogwai, Design and fabrication of a miniature tensile load frame for a scanning electron microscope, Senior Design Team 04-004, Critical Design Report, 2004.

[9] H. Giberti, S. Cinquemani, G. Legnani, A practical approach to the selection of the motor-reducer unit in electric drive systems, Mech. Based. Des. Struct. Mach., 39 (2011) 303-319.

https://doi.org/10.1080/15397734.2011.543048

[10] J. M. Brown, K. Potter, S. Foster, T. Batho, The development of a high temperature tensile testing rig for composite laminates, Compos. Part. A: Appl. Sci. Manuf., 52 (2013) 99-105.

https://doi.org/10.1016/i.compositesa.2013.04.009

[11]R. Gedney, Understanding a universal testing machine motor control system, Admet, (2019).

[12] Z. Mdletshe, Design and manufacturing of a temperature controlled chamber for a tensile testing machine, thesis ,master of engineering: mechanical engineering, Cape Peninsula University of Technology. (2017). 
[13] S. Gulpanich, V. Krongratana, A. Srimuang, V. Tipsuwanporn, N. Wongvanich, PLC-based industrial temperature controller with different response times, Int. Conf. Control. Autom. Syst., 2017 (2017) 522-527. https://doi.org/10.23919/ICCAS.2017.8204291

[14] G. Rata, M. Rata, Temperature control solution with PLC, Proc. Int. Conf. Expo. Electr. Power. Eng., 2016 (2016) 571-575. https://doi.org/10.1109/ICEPE.2016.7781405

[15] D. Rajput, A. Singh, S. Kumar, Evaluation of Johnson-Cook Material Model Parameters of AA6063-T6. 7(2020) 1476-1481. 